THE airway epithelium is responsible for the production of a number of arachidonic acid and nonprostanoid inhibitory factors. Epithelium synthesises nitric oxide (NO) which may be important in regulating the function of airways smooth muscles. We studied in vitro the effect of histamine (100 nM$100 \mu \mathrm{M})$ which increases the NO release on rabbit airway smooth muscles induced by $80 \mathrm{~m} \mathrm{M} \mathrm{KCl}$ in the presence or not of $10^{-5}$ Methylene blue (MB) (inactivator of guanylate cyclase) or $\mathrm{N}(\mathrm{G})$-monomethyl L-argin in e (L-NMMA), a NOS inhibitor. All experiments were done in tracheal muscle strips from 28 rabbits with epithelium and after epith elium removal. The additional use of histamine $(1 \mu \mathrm{M})$ on $\mathrm{KCl}$ contraction induced a relaxation of $10 \%$ of the in itial contraction. The additional use of L-NMMA decreased the relaxation to $5 \%$ of in itial contraction. MB rather than L-NMMA increased the contraction significantly $(\boldsymbol{p}<\mathbf{0 . 0 1})$. Epithelium removal increased the contraction induced by $\mathrm{KCl}(80 \mathrm{mM})$ and histam ine $(1 \mu \mathrm{M})$ by about $30 \%(p<0.001)$. NO release especially from epithelium regulates the airways smooth muscle functions. Damage to the epithelium may contribute to an increase in airways sensitivity, observed in as th $\mathrm{m}$ a.

Key words: Nitric oxide, Histamine, Epithelium, Bronchial asthma

\section{Epithelium-dependent regulation of airways smooth muscle function. A histamine-nitric oxide pathway}

\author{
Konstantinos Gourgoulianis, ${ }^{\text {CA }}$ Zoe Iliodromitis, \\ Apostolia Hatziefthimiou and \\ Paschalis-Adam Molyvdas
}

Department of Physiology, Medical School, University of Thessaly, Larissa, Greece

${ }^{\mathrm{CA}}$ Corresponding Author
Tel: (+41) 532501
Fax: (+41) 255420
Email: Kgourg@uth.gr

\section{Introduction}

Bronchial asthma is an inflammatory disorder involving a variety of cells and mediators. The denudation of the epithelium, the mucous plugging, the collagen deposition beneath the epithelial basement membrane, the edema of submucosa and the infiltration of eosinophils have been recognized to be major features in many patients with status asthmaticus. ${ }^{1}$ Although it was believed that airway epithelial cells functioned as a passive protective barrier, now it is clear that these cells may also participate in the inflammatory response. Epithelial cells may release mediators and produce nitric oxide (NO) which may amplify asthmatic inflammation in the airways. ${ }^{2} \mathrm{NO}$ is a neurotransmitter of inhibitory nonadrenergic non-cholinergic nerves with a short half life. ${ }^{3}$ Mediators such as histamine effect $\mathrm{NO}$ synthesis by modulating nitric oxide synthases (NOS). These factors most likely affect $\mathrm{NO}$ by modulating intracellular $\mathrm{Ca}^{++}$, which regulates the constitutive NOS resulting in a rapid increase in NO, whereas the cytokines increase $\mathrm{NO}$ more slowly by increasing mRNA transcription for the inducible NOS. Stimulation of the epithelial layer by $0.1 \mu \mathrm{M}$ histamine increased the release of NO 3-4-fold compared to basal levels. ${ }^{4}$

In this study we investigated the role of the epithelium, specifically the pathway of NO in the regulation of airways smooth muscle functions.

\section{Methods}

Portions of tracheas were obtained from rabbits (1-2 kg body weight) that had been anaesthetized with pentothal. Muscle strips $(2-3 \mathrm{~mm})$ taken from the tracheas were superfused lumenal side up under $1 \mathrm{~g}$ of tension in a bathing chamber that was continuously perfused with Kerbs solution with the follow ing composition (in $\mathrm{mM}$ ): $\mathrm{Na}^{+} 137, \mathrm{Mg}^{2+} 1.1$, $\mathrm{K}^{+}$5.9, $\mathrm{Cl}^{-} 123, \mathrm{Ca}^{2+} 2, \mathrm{H}_{2} \mathrm{PO}_{4}^{-} 1.2, \mathrm{HCO}_{3}^{-}$24.9, glucose 9.6 (gassed with $95 \% \mathrm{O}_{2}$ and $5 \% \mathrm{CO}_{2}, \mathrm{pH}$ $\left.7.4,37^{\circ} \mathrm{C}\right)$. Changes in tension were recorded on a Grass FTO3C force displacement transducer and displayed on a Universal oscillograph (Harvard) recorder. We studied the effect of histamine $(100 \mathrm{nM}-100 \mu \mathrm{M})$ on contractions induced by elevating the extracellular $\left[\mathrm{K}^{+}\right]_{\mathrm{o}}$ concentration to $80 \mathrm{mM}$, by isosmotic substitution with $\left[\mathrm{Na}^{+}\right]_{\mathrm{o}}$ in the presence (or not) of $10^{-5}$ Methylene blue (MB) 


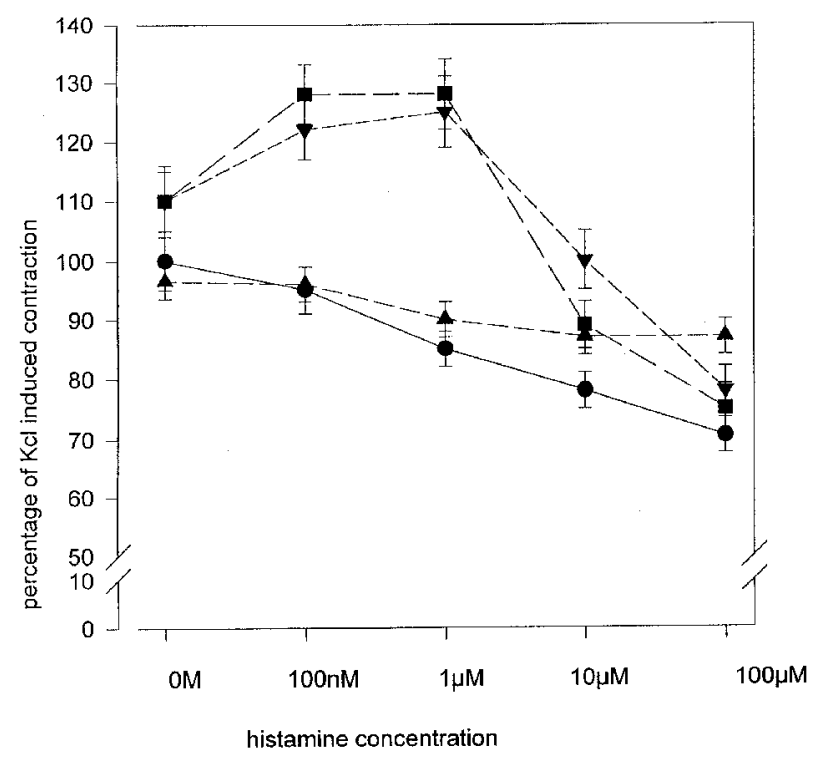

FIG. 1. Dose response curve of histamine in $\mathrm{KCl}$ induced contraction: without epithelium; $\boldsymbol{\nabla}$ epithelium and methylene blue; $\boldsymbol{\Delta}$ epithelium and NMMA; $\bullet$ epithelium.

(inactivator of guanylate cyclase) or $\mathrm{N}(\mathrm{G})$-monomethyl L-arginine (L-NMMA), a NOS inhibitor. All these experiments were done on tracheal strips before and after epithelium removal. We used tracheal muscle strips from 28 rabbits, seven for each separate experiment. A $t$-test was used to detect differences between groups.

\section{Results}

The results of our study (see Fig. 1) showed that the additional use of histamine $(1 \mu \mathrm{M})$ for $\mathrm{KCl}$ contraction induced a relaxation of $10 \%$ of the initial contraction. The additional use of L-NMMA decreased the relaxation to $5 \%$ of initial contraction. Despite this data the use of $M B$ instead of L-NMMA increased the contraction significantly $(p<0.01)$. Epithelium removal increased the contraction induced from $\mathrm{KCl}(80 \mathrm{mM})$ and histamine $(1 \mathrm{mM})$ by about $30 \%(p<0.001)$.

\section{Discussion}

The aim of this study is the simultaneous use of histamine and $\mathrm{KCl}$. Histamine induced an increase in intracellular $\mathrm{Ca}^{++}$via receptor-operated channels and $\mathrm{KCl}$ via voltage-dependent channels. In excitable cells like airways smooth muscle $\mathrm{Ca}^{++}$influx is generally accomplished by voltage dependent $\mathrm{Ca}^{++}$ channels. In non-excitable cells like epithelial cells in the airways, voltage-operated $\mathrm{Ca}^{++}$channels are not expressed. In these cells store-operated $\mathrm{Ca}^{++}$ entry, where $\mathrm{Ca}^{++}$influx is specifically controlled by the filling state of the intracellular $\mathrm{Ca}^{++}$stores, is the predominant pathway. ${ }^{5}$ The intracellular $\mathrm{Ca}^{++}$ concentration of epithelium response to agonists such as histamine is biphasic consisting of an initial transient rise which is independent of extracellular $\mathrm{Ca}^{++}$followed by sustained elevation mediated by $\mathrm{Ca}^{++}$influx. There is a close correlation between intracellular $\mathrm{Ca}^{++}$mobilization and $\mathrm{NO}$ release in epithelial cells stimulated with histamine. NOs activate guanylate cyclase, raise c-GMP levels and induce relaxation of the isolated airway smooth muscle. ${ }^{6}$

In our study the elevation of epithelial NO production induced from histamine in addition to acute intracellular increase of airways smooth muscle $\mathrm{Ca}^{++}$, stimulated cytosolic guanylate cyclase to generate cGMP. The above interaction between airways epithelium and muscles is the main reason for the relaxation. In our in vitro study the use of L-NMMA inhibits NOS and the epithelial production of NO. The pathway of relaxation is disrupted and the previous relaxation is reduced. $M B$ inactivates guanylate cyclase in the airway muscles which results in an end to the relaxation process and an increase of initial contraction. However, the removal of epithelium induced the previous contraction further. In man damage to epithelial cells could affect airways homeostasis, because the epithelial layer interacts with smooth muscles. The production of nitric oxide is decreased in guinea pig airways after a viral infection and is associated with hyper-responsiveness. Epithelial cells release other relaxing factors such as prostaglandin $\mathrm{E}_{2}$ and metabolize inflammatory mediators. ${ }^{5}$

Epithelial injury and bronchial hyper-responsiveness are commonly associated with airway diseases such as asthma and are considered to occur as a result of inflammatory changes in the airway wall. Corticosteroids which have assumed a dominant role in asthma therapy, directly decrease production of NO from airway epithelial cells but indirectly attenuate TNF-a and IL-1 $\beta$ release from macrophages and reduce epithelial NO production. ${ }^{7}$ However the pathway of endogenous NO which begins from epithelium receptors of mediators in addition to rapid increase of $\mathrm{Ca}^{++}$intracellularly is a main physiologic route of relaxation in airways smooth muscles.

In summary the epithelium modulates other structural components of the airways such as airways smooth muscles by a number of mechanisms including NO production. Damage to the epithelium may contribute to the increase in airways sensitivity observed in asthma. More extensive evaluation of new therapies which modulate airway epithelial function together with anti-inflammatory properties may be a target for asthma treatment. 


\section{References}

1. Lemanske RF, Busse WW. Asthma. JAMA 1997; 278: 1855-1873.

2. Holtzman MJ. Arachidonic acid metabolism in airw ay e pithelial cells. Ann Rev Physiol 1992; 54: 303-329.

3. Chow ienczyk P, Ritter J. Arginine: NO more than a simple aminoacid? Lancet 1997; 350: 901-902.

4. Sadeghi-Hashjin G, Henricks PA, Folkerts G, Verheyen AK, Van der Linde HJ, Nijkamp FP. Bovine tracheal responsiveness in vitro: role of the epithelium and nitric oxide. Eur Respir J 1996; 9: 2286-2293.
5. Parekh AB, Penner R. Store depletion and calcium influx. Physiol Rev 1997; 77: 901-930.

6. Hutcheson IR, Griffith TM. Central role of intracellular calcium stores in acute flow- and agonist-evoked endothelial nitric oxide release. $\mathrm{Br} J$ Pharmacol 1997; 122: 117-125.

7. Spahn JD, Leung DYM. The role of glucorticoids in the management of asthma. Allergy Asthma Proc 1996; 17: 341-350.

\section{Received 11 August 1998;} accepted 5 September 1998 


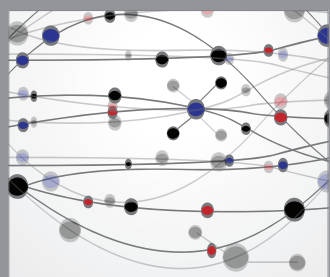

The Scientific World Journal
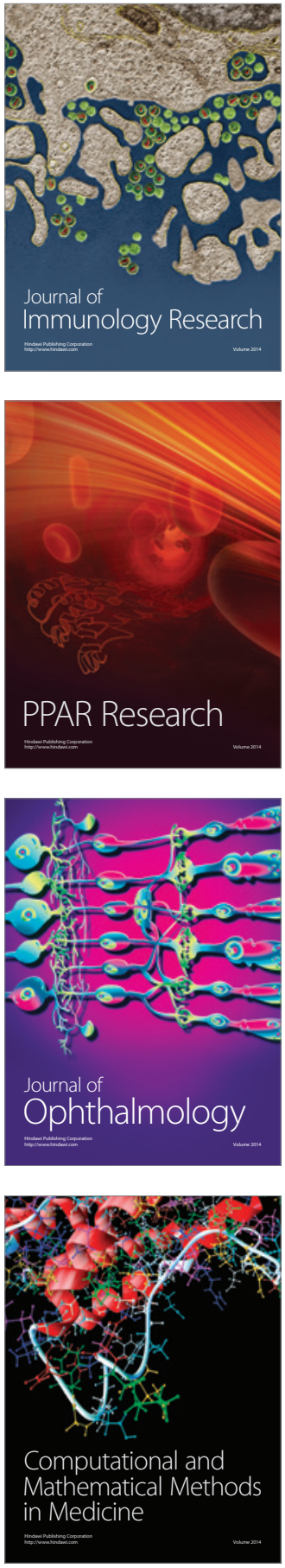

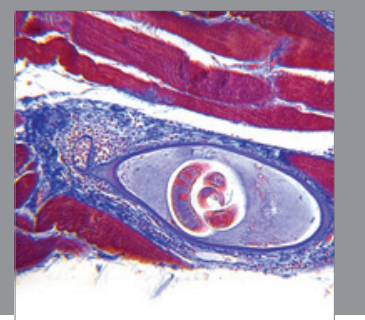

Gastroenterology

Research and Practice
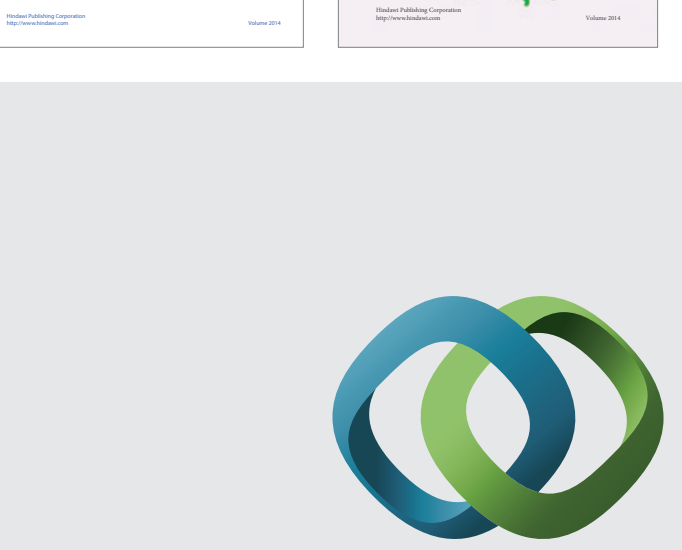

\section{Hindawi}

Submit your manuscripts at

http://www.hindawi.com
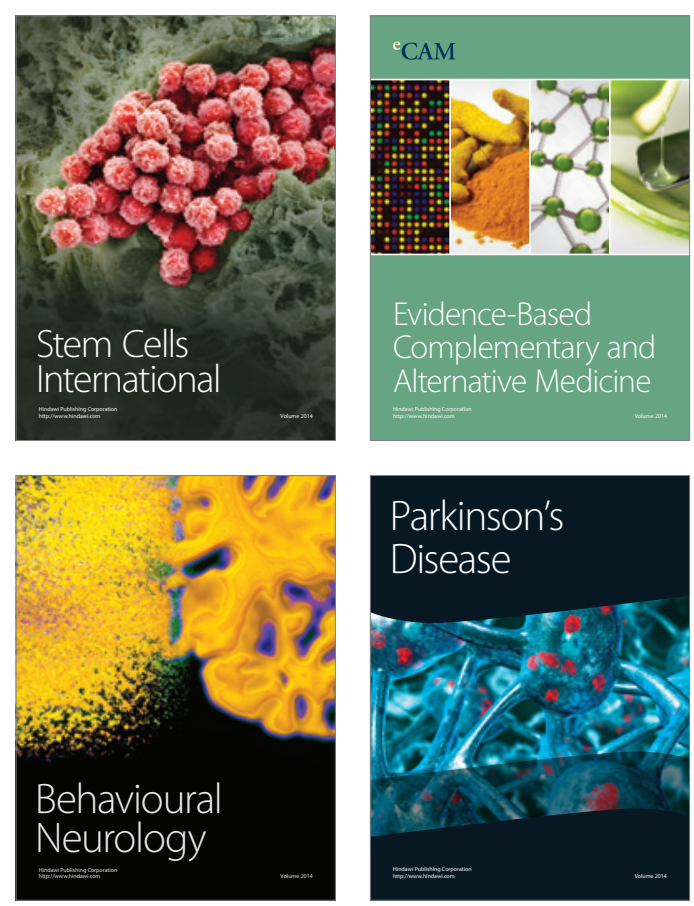

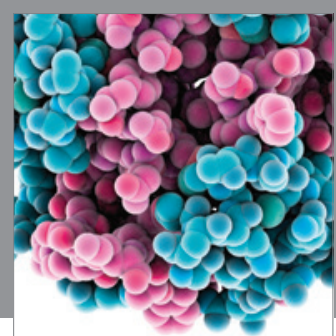

Journal of
Diabetes Research

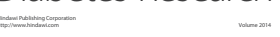

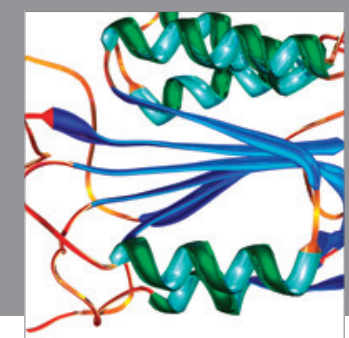

Disease Markers
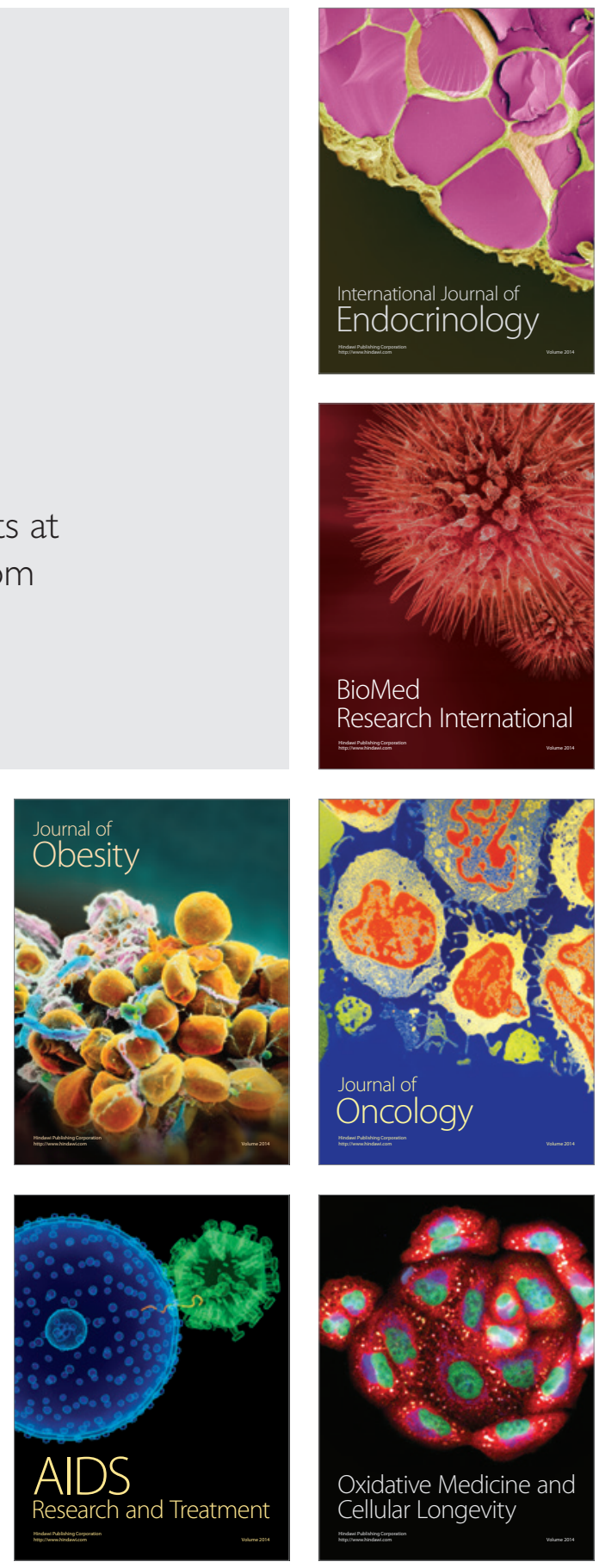